\title{
Echocardiographically based treatment of chronic ischemic mitral regurgitation
}

\author{
Antonio M. Calafiore, MD, ${ }^{\mathrm{a}}$ Angela L. Iacò, MD, ${ }^{\mathrm{a}}$ Antonio Bivona, MD, ${ }^{\mathrm{b}}$ Egidio Varone, MD, \\ Salvo Scandura, MD, ${ }^{\mathrm{b}}$ Patrizia Greco, MD, ${ }^{\mathrm{b}}$ Antonella Romeo, MD, ${ }^{\mathrm{b}}$ and Michele Di Mauro, $\mathrm{MD}^{\mathrm{c}}$
}

Objectives: We evaluated results of an echocardiographically based strategy combining mitral annuloplasty with other procedures to treat chronic ischemic mitral regurgitation.

\begin{abstract}
Methods: From March 2006 to February 2009, 147 patients underwent mitral valve surgery for chronic ischemic mitral regurgitation. Mean effective regurgitant orifice was $36 \pm 11 \mathrm{~mm}^{2}$, and ejection fraction was $35 \% \pm 9 \%$. On the basis of echocardiographic findings, in 10 cases a prosthesis was inserted and mitral annuloplasty was performed in 137 cases, isolated in 83, associated with chordal cutting in 12 cases (in 5 anterior leaflet was augmented with pericardial patch), and with exclusion of anteroseptal $(n=35)$ or inferior $(n=7)$ scars in 42 .
\end{abstract}

Results: Thirty-day mortality was $4.8 \% ; 3$-year survival was $86 \% \pm 3 \%$. None of the 126 survivors were in New York Heart Association functional class III or IV. Among 117 survivors of mitral valve repair, after $18 \pm 6$ months mean effective regurgitant orifice reduced from $34.1 \pm 10.2 \mathrm{~mm}^{2}$ to $2.3 \pm 0.4 \mathrm{~mm}^{2}(P<.001)$. Nine patients showed residual effective regurgitant orifice 10 to $19 \mathrm{~mm}^{2}$. Reverse remodeling was present in 69 patients $(59.0 \%)$, no remodeling in $40(34.1 \%)$, and continuous remodeling in $8(6.9 \%)$. Ejection fraction changed from $37 \% \pm 10 \%$ to $43 \% \pm 10 \%(P<.001)$, improving in 47 , remaining unchanged in 63 , and worsening in 7 .

Conclusions: Echocardiographically based strategy contributed to reduced postoperative mitral regurgitation persistence (effective regurgitant orifice $\geq 10 \mathrm{~mm}^{2}$ in $7.7 \%$ of cases, with no patients showing effective regurgitant orifice $\geq 20 \mathrm{~mm}^{2}$ ). All patients remained in New York Heart Association functional class I or II, but more than mitral annuloplasty was performed in close to 40\%. (J Thorac Cardiovasc Surg 2011;141:1150-6)

丹 Supplemental material is available online.

Video clip is available online.

Treatment of chronic ischemic mitral regurgitation (CIMR) still remains a challenge. Results from the literature are not uniform, and principles of surgical treatment are not clearly stated. In particular, there is no agreement as to either devices to be used (ring, band, rigid, semirigid, flexible, shaped, unshaped, and so on) or which patients \can benefit from mitral valve (MV) surgery. Furthermore, many articles report experiences related to periods when the knowledge both of the

From the Department of Adult Cardiac Surgery, ${ }^{a}$ Prince Sultan Cardiac Center, Riyadh, Kingdom of Saudi Arabia; the Department of Cardiology and Cardiac Surgery, ${ }^{\mathrm{b}}$ Ferrarotto Hospital, University of Catania, Italy; and the Division of Cardiac Surgery, ${ }^{\mathrm{c}}$ Villa Bianca, Bari, Italy.

Disclosures: Authors have nothing to disclose with regard to commercial support.

Received for publication Jan 29, 2010; revisions received June 14, 2010; accepted for publication July 5, 2010; available ahead of print Aug 16, 2010.

Address for reprints: Antonio M. Calafiore, MD, Professor of Cardiac Surgery, Director, Department of Adult Cardiac Surgery, Prince Sultan Cardiac Center, Riyadh, Kingdom of Saudi Arabia (E-mail: calafiore@unich.it).

$0022-5223 / \$ 36.00$

Copyright (c) 2011 by The American Association for Thoracic Surgery doi:10.1016/j.jtcvs.2010.07.008 physiology of the MV and of the pathophysiology of CIMR was not complete. Suboptimal results also reflect lack of standardization of surgical strategies. ${ }^{1-4}$ We report here our recent experience, in which surgical treatment of CIMR was not limited to annuloplasty alone and different strategies were applied according to echocardiographic data.

\section{MATERIALS AND METHODS}

From March 2006 to February 2009, a total of 147 patients underwent their first cardiac procedure, MV surgery for CIMR caused by inferior $(\mathrm{n}=110,81 \%)$ or anterior $(\mathrm{n}=37,19 \%)$ myocardial infarction. Only patients in cardiogenic shock when operated on were excluded.

\section{Definition}

CIMR is defined as any mitral regurgitation that is due to excess of tethering of either or both leaflets as a result of misalignment of either or both of the papillary muscles. All the patients in this series had a previous myocardial infarction with regional wall abnormalities.

\section{Echocardiographic Evaluation}

In all cases, the following data were evaluated: intercommissural and septolateral distances (systolic and diastolic), ratio of septolateral to intercommissural distance (systolic), length of anterior leaflet (AL), tenting area, coaptation depth (CD), coaptation length (CL), left ventricular indexed end-systolic volume (ESV) and end-diastolic volume, ejection fraction (EF), and sphericity index. The mitral annulus was assessed in apical long-axis 4- and 2-chamber views. The distance between the points where MV leaflets coapt and mitral annulus plane (CD) was measured at the end of systole in the 4-chamber apical long-axis view. The mitral areas in diastole and systole were calculated as the MV were an ellipsoid $(\pi / 4 \cdot \mathrm{SL} \cdot \mathrm{IC})$, where $S L$ represents the septolateral distance and $I C$ the intercommissural 


$$
\begin{aligned}
& \text { Abbreviations and Acronyms } \\
& \begin{aligned}
\text { AL } & =\text { anterior leaflet } \\
\text { CIMR } & =\text { chronic ischemic mitral regurgitation } \\
\text { CD } & =\text { coaptation depth } \\
\text { CL } & =\text { coaptation length } \\
\text { EF } & =\text { ejection fraction } \\
\text { ERO } & =\text { effective regurgitant orifice } \\
\text { ESV } & =\text { end-systolic volume } \\
\text { MV } & =\text { mitral valve } \\
\text { NYHA } & =\text { New York Heart Association }
\end{aligned}
\end{aligned}
$$

distance. Mitral area change was then calculated as (DMA - SMA)/ DMA $\cdot 100 \%$, where DMA represents the mitral area during diastole and SMA that during systole. Left ventricular volumes and EF were measured according to the biapical Simpson disk method. Evaluation of mitral regurgitation grade was performed by using the effective regurgitant orifice (ERO) to evaluate mitral regurgitation severity, in accordance with Grigioni and colleagues. ${ }^{5}$ CIMR was considered severe if ERO was at least $20 \mathrm{~mm}^{2}$, moderate if ERO was 10 to $19 \mathrm{~mm}^{2}$, and mild if ERO was 1 to $9 \mathrm{~mm}^{2}$. Table 1 shows the echocardiographic results from the study group.

\section{Surgical Indications}

All patients with CIMR with an ERO of at least $10 \mathrm{~mm}^{2}$ were candidates for MV surgery. In cases of ERO 1 to $9 \mathrm{~mm}^{2}$, the decision regarding MV repair depended on the echocardiographically demonstrated MV anatomy. The median values of septolateral dimension in systole and of the ratio of systolic septolateral dimension to AL length in patients with ERO of at least $10 \mathrm{~mm}^{2}$ treated during the study time frame were, respectively, $27 \mathrm{~mm}$ and 1.02 (Table E1). If either of these values was reached in a patient with ERO 1 to $9 \mathrm{~mm}^{2}$, we hypothesized that the consequence was a dangerous $\mathrm{CL}$ reduction and that surgical treatment was therefore advisable.

$\mathrm{ACD}$ of $10 \mathrm{~mm}$ or less was the limit for MV repair. If the CD was 11 or more, the anatomy was not considered suitable for repair, and a prosthesis was inserted into the MV. ${ }^{6}$ If the left ventricle was dilated, nuclear magnetic resonance imaging was performed to evaluate the presence of ventricular scars to be excluded.

When the MV was suitable for repair, we analyzed the length of the AL and the presence of AL excess of tethering. Because the purpose of surgery was to obtain a competent MV with a CL from 4 to $8 \mathrm{~mm}$, we accepted an $\mathrm{AL}$ length of at least $25 \mathrm{~mm}$. If not, we augmented its surface with a pericardial patch. Excess of AL tethering could also be a factor in reduced CL. In such cases, second-order chordae were cut through an aortotomy. Because augmentation of AL could also increase second-order chordal tethering, the second-order chordae were cut every time we augmented the AL surface.

Figure 1 summarizes our algorithm for echocardiographically based surgical indications.

\section{Surgical Technique}

After a median sternotomy, the ascending aorta and both venae cavae were cannulated, the superior vena cava directly. The MV was approached transseptally through a right atriotomy. The mitral annulus was always reshaped with

\begin{tabular}{|c|c|}
\hline $\begin{array}{l}\text { End-diastolic volume }\left(\mathrm{mL} / \mathrm{m}^{2} \text {, mean } \pm \mathrm{SD}\right. \\
\text { and median) }\end{array}$ & $83 \pm 25(82)$ \\
\hline $\begin{array}{l}\text { End-systolic volume }\left(\mathrm{mL} / \mathrm{m}^{2} \text {, mean } \pm \mathrm{SD}\right. \\
\text { and median) }\end{array}$ & $55 \pm 21(54)$ \\
\hline Ejection fraction $(\%$, mean $\pm \mathrm{SD}$ and median $)$ & $35 \pm 9(35)$ \\
\hline Ejection fraction $\leq 30 \%$ (no.) & $52(35.4 \%)$ \\
\hline Sphericity index (mean \pm SD and median) & $0.63 \pm 0.10(0.6)$ \\
\hline \multicolumn{2}{|l|}{$\begin{array}{l}\text { Mitral regurgitation effective regurgitant } \\
\text { orifice }\left(\mathrm{mm}^{2}\right)\end{array}$} \\
\hline Mean $\pm \mathrm{SD}$ and median & $36 \pm 11(34)$ \\
\hline $1-9 \mathrm{~mm}^{2}$ (no.) & $5(3.5 \%)$ \\
\hline $10-19 \mathrm{~mm}^{2}$ (no.) & $18(12.2 \%)$ \\
\hline$\geq 20 \mathrm{~mm}^{2}$ (no.) & $124(84.3 \%)$ \\
\hline $\begin{array}{l}\text { Diastolic intercommissural diameter } \\
\quad(\mathrm{mm}, \text { mean } \pm \mathrm{SD} \text { and median })\end{array}$ & $34 \pm 3(33)$ \\
\hline $\begin{array}{l}\text { Systolic intercommissural distance }(\mathrm{mm} \text {, mean } \pm \mathrm{SD} \\
\text { and median) }\end{array}$ & $32 \pm 3(31)$ \\
\hline $\begin{array}{l}\text { Diastolic septolateral diameter }(\mathrm{mm} \text {, mean } \pm \mathrm{SD} \\
\text { and median) }\end{array}$ & $31 \pm 3(30)$ \\
\hline $\begin{array}{l}\text { Systolic septolateral diameter }(\mathrm{mm} \text {, mean } \pm \mathrm{SD} \\
\text { and median) }\end{array}$ & $29 \pm 3(28)$ \\
\hline Diastolic mitral area $\left(\mathrm{cm}^{2}\right.$, mean $\pm \mathrm{SD}$ and median) & $8.3 \pm 1.4(8.0)$ \\
\hline Systolic mitral area $\left(\mathrm{cm}^{2}\right.$, mean $\pm \mathrm{SD}$ and median) & $7.3 \pm 1.3(7.1)$ \\
\hline Mitral area change $(\%$, mean \pm SD and median $)$ & $12 \pm 2(11)$ \\
\hline Anterior leaflet length (mm, mean $\pm \mathrm{SD}$ and median) & $27 \pm 3(27)$ \\
\hline Anterior leaflet length $<25 \mathrm{~mm}$ (no.) & $5(3.5 \%)$ \\
\hline $\begin{array}{l}\text { Septolateral diameter/anterior leaflet length } \\
\qquad(\text { mean } \pm \mathrm{SD} \text { and median })\end{array}$ & $1.04 \pm 0.12(1.02)$ \\
\hline Coaptation depth (mm, mean \pm SD and median) & $7.9 \pm 2.3(7)$ \\
\hline Coaptation length (mm, mean \pm SD and median) & $3.6 \pm 1.8(4)$ \\
\hline Tenting area $\left(\mathrm{cm}^{2}\right.$, mean $\pm \mathrm{SD}$ and median $)$ & $1.5 \pm 1.0(1.35)$ \\
\hline $\begin{array}{l}\text { Tricuspid regurgitation }(0-4 \text {, mean } \pm \text { SD } \\
\text { and median) }\end{array}$ & $1.5 \pm 0.9(1)$ \\
\hline $\begin{array}{l}\text { Systolic pulmonary arterial pressure } \\
\text { (mm } \mathrm{Hg}, \text { mean } \pm \mathrm{SD} \text { and median })\end{array}$ & $36 \pm 10(33)$ \\
\hline
\end{tabular}
the SMB40 (Sorin Biomedica SpA, Saluggia, Italy). The band, 40-mm long, was inserted from A1 (that coincides with the left trigone) to A3 (the fibrous zone that represents the offshoots of the right trigone) with several interrupted sutures, leaving the only A2 insertion free (Video E1). Because the surgical technique is the same for all the annuli, independent of size, all sutures (in general, 8 to 10) are imbricated to reduce the stress on the single suture.

Insertion of a prosthesis inside the MV was obtained by cutting only a triangle of the $\mathrm{AL}$ with the base at $\mathrm{AL}$ insertion and the apex at the midpoint of
TABLE 1. Preoperative echocardiographic data $(n=147)$

A2. The remainder of the AL was pushed toward the annulus with the prosthetic sutures. ${ }^{6}$

Any short $(<25 \mathrm{~mm})$ AL was disconnected from its insertion, and a pericardial patch $(23 \times 12 \mathrm{~mm})$ was used to extend its height. The second-order chordae were always cut to provide better mobility of the leaflet. When the second-order chords tethered the AL excessively, an aortotomy was performed, and these chordae were cut to increase the mobility of the leaflet (Video E2).

Different techniques were used to exclude ventricular scars. In the case of inferior scar, an incision parallel to the descending posterior artery was performed, and the scar was longitudinally excluded with interrupted $\mathrm{U}$ sutures. If the scar was limited to the apex and to the apical septum, a Dor procedure (purse-string with or without patch) was used. If the scar involved the septum more than the anterior free wall, a septal reshaping was performed. The purpose of these procedures was always to rebuild a conical shape.

Tricuspid repair was performed with a De Vega suture annuloplasty or a band annuloplasty.

\section{Follow-up}

All patients were clinically followed up in our outpatient clinic 3, 6, and 12 months after surgery and thereafter at yearly intervals. The most recent information was obtained by calling the patient or the referring cardiologists. Follow-up was $100 \%$ complete. Mean follow-up time was $18 \pm 6$ months. 


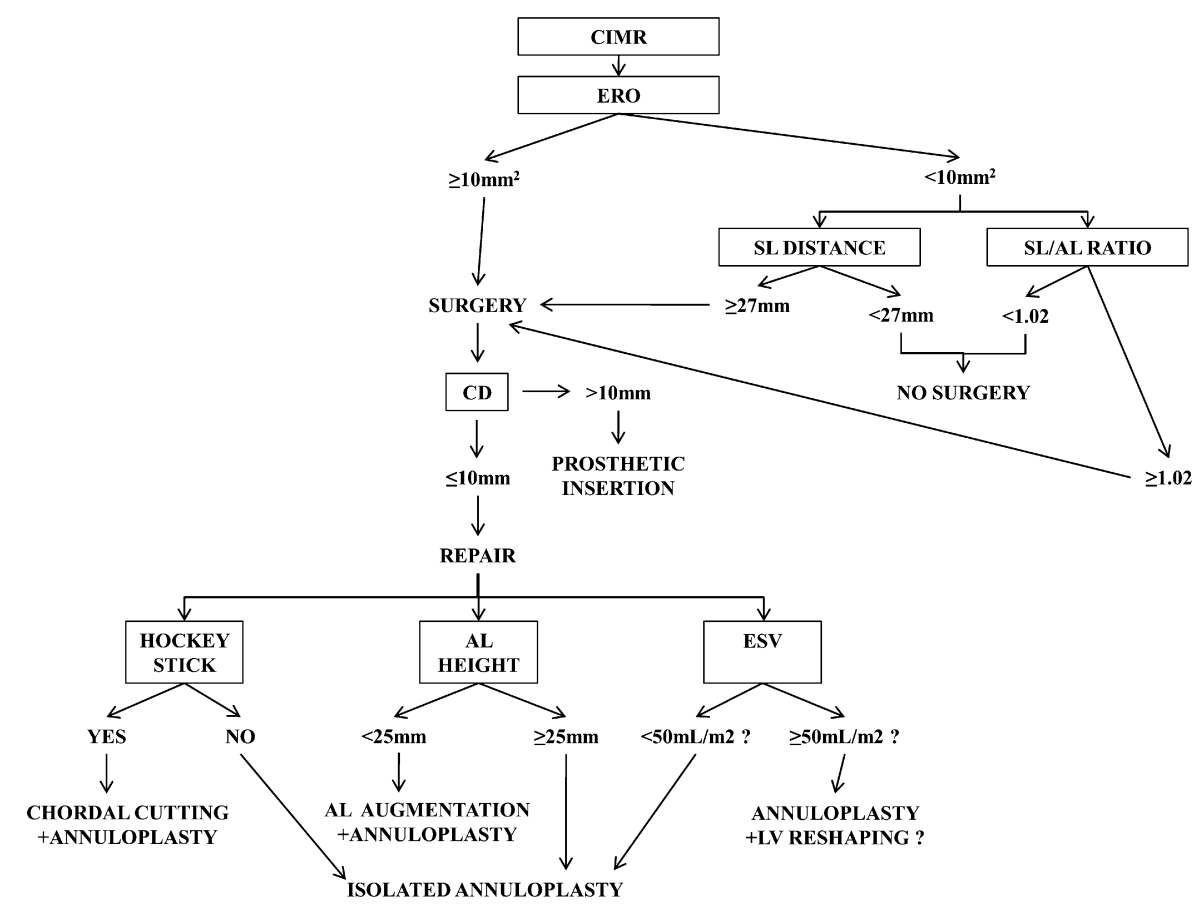

FIGURE 1. Algorithm for indications for different surgical procedures. CIMR, Chronic ischemic mitral regurgitation; $E R O$, effective regurgitant orifice; $S L$, systolic septolateral diameter; $A L$, anterior leaflet; $C D$, coaptation depth; $E S V$, end-systolic volume.

\section{Echocardiographic Evaluation, Ventricular Remodeling, and EF Modifications}

Every patient had at least 1 echocardiographic control during the followup. Time from surgery to the last control was $17 \pm 5$ months (median 18 months). Modifications of the indexed end-diastolic volume and indexed ESV were evaluated as percentages of the preoperative values. Reverse remodeling was defined as any reduction by $15 \%$ or more, continuous remodeling as any increase by $15 \%$ or more, and no remodeling as a modification of the postoperative value between $+14 \%$ and $-14 \%$. EF was considered improved if the control value increased by $15 \%$ or more of its base value, unchanged if it remained between $-14.9 \%$ and $+14.9 \%$, and worsened if reduced by more than $15 \%$.

\section{End Points}

The primary end points of this study were our clinical and echocardiographic results after an echocardiographically based strategy for the treatment of CIMR.

\section{Statistical Analysis}

Results are expressed as mean \pm SD and median values. Categoric variables are reported as counts and percentages. Echocardiographic modifications with time were evaluated with the analysis of variance test for repeated measure (with post hoc analysis). Survival was evaluated by Kaplan-Meier method. The optimal cutoff was determined by receiver operating characteristic curve analysis. The influence of preoperative ESV on midterm ventricular remodeling grade was investigated by means of linear regression. The SPSS software package (SPSS Inc, an IBM Company, Chicago, Ill) was used.

\section{RESULTS}

One hundred thirty-seven patients $(93.2 \%)$ underwent MV repair, and in $10(6.8 \%)$ a prosthesis was inserted inside the MV, more often in case of ventricular surgery ( $7 / 42 \mathrm{vs} 3 /$ $105, P=.008)$. The AL was augmented in 5 cases $(3.4 \%)$; in all of them, the second-order chordae were cut. In 7 other patients, second-order chordae were electively cut through an aortotomy. Ventricular scar exclusion was performed in 42 cases $(28.6 \%)$ : linear resection of scarred inferior wall in 7 cases $(4.7 \%)$, septal reshaping in $29(19.7 \%)$, and a Dor procedure in $6(4.2 \%)$. In total, $39 \%$ of the patients (57/147) underwent annuloplasty combined with other procedures. Coronary artery bypass grafting was performed in 135 patients $(91.8 \%)$ and tricuspid repair in 51 patients $(34.7 \%)$.

\section{Survival}

Seven patients ( $4.8 \%$ ) died during the first month. Causes of death were pulmonary complications in 3 cases, low output syndrome in 2, arrhythmias in 1, and coagulopathy in 1 . After a mean follow-up of $7 \pm 3$ months, 13 more patients died of cardiac $(n=7)$ and noncardiac causes $(n=6)$. Mean follow-up of the 127 survivors was $20 \pm 9$ months. The 3-year freedoms from death from any cause and from cardiac-related death were $86 \% \pm 3 \%$ and $90 \% \pm 3 \%$, respectively.

\section{Functional Results}

Mean New York Heart Association (NYHA) functional class was $1.3 \pm 0.5$, with 90 patients in NYHA class I, 36 in NYHA class II, and 1 in class III. NYHA functional class 
TABLE 2. Echocardiographic control in 117 patients who underwent mitral valve repair

\begin{tabular}{|c|c|c|c|}
\hline & \multirow[b]{2}{*}{ Preoperative } & \multicolumn{2}{|c|}{ Postoperative } \\
\hline & & Early & Midterm \\
\hline End-diastolic volume index $\left(\mathrm{mL} / \mathrm{m}^{2}\right)$ & $84 \pm 24(79)$ & $71 \pm 17(74)^{*}$ & $67 \pm 16(68) \dagger$ \\
\hline End-diastolic volume index $\left(\mathrm{mL} / \mathrm{m}^{2}\right)$ & $55 \pm 20(49)$ & $45 \pm 14(42)^{*}$ & $40 \pm 12(38) \dagger, \ddagger$ \\
\hline Ejection fraction $(\%)$ & $37 \pm 10(36)$ & $39 \pm 9(38)$ & $43 \pm 10(42) \dagger, \ddagger$ \\
\hline Sphericity index & $0.63 \pm 0.09(0.6)$ & $0.58 \pm 0.09(0.57)^{*}$ & $0.59 \pm 0.08(0.6) \dagger$ \\
\hline Tricuspid regurgitation $(0-4)$ & $1.4 \pm 0.7(1)$ & $0.7 \pm 0.6(1)^{*}$ & $0.8 \pm 0.7(1) \dagger$ \\
\hline Systolic pulmonary arterial pressure $(\mathrm{mm} \mathrm{Hg})$ & $36 \pm 11(33)$ & $29 \pm 5(29)^{*}$ & $28 \pm 8(28) \ddagger$ \\
\hline Mitral effective regurgitant orifice $\left(\mathrm{mm}^{2}\right)$ & $34.1 \pm 10.2(33)$ & $1.5 \pm 0.1(0)^{*}$ & $2.3 \pm 0.4(0) \dagger, \ddagger$ \\
\hline Diastolic intercommissural diameter $(\mathrm{mm})$ & $33 \pm 3(33)$ & $27 \pm 3(27)^{*}$ & $27 \pm 2(27) \dagger$ \\
\hline Systolic intercommissural diameter $(\mathrm{mm})$ & $31 \pm 3(30)$ & $24 \pm 2(24)^{*}$ & $24 \pm 3(24) \dagger$ \\
\hline Diastolic septolateral diameter (mm) & $30 \pm 23(29)$ & $25 \pm 3(24)^{*}$ & $25 \pm 2(25) \dagger$ \\
\hline Systolic septolateral diameter $(\mathrm{mm})$ & $28 \pm 3(27)$ & $21 \pm 2(21)^{*}$ & $21 \pm 2(21) \dagger$ \\
\hline Diastolic mitral area $\left(\mathrm{cm}^{2}\right)$ & $7.8 \pm 1.3(7.5)$ & $5.3 \pm 1.3(5.2)^{*}$ & $5.3 \pm 1.0(5.3) \dagger$ \\
\hline Systolic mitral area $\left(\mathrm{cm}^{2}\right)$ & $6.8 \pm 1.2(6.5)$ & $3.9 \pm 1.8(3.8)^{*}$ & $3.9 \pm 0.9(4.1) \dagger$ \\
\hline Mitral area change $(\%)$ & $12.8 \pm 5.2(15.6)$ & $26.3 \pm 4.7(26.0)^{*}$ & $26.4 \pm 3.0(22.4) \dagger$ \\
\hline $\mathrm{AL}(\mathrm{mm})$ & $27 \pm 2(27)$ & & \\
\hline Septolateral diameter/AL & $1.04 \pm 0.1(1)$ & $0.78 \pm 0.11(0.78)^{*}$ & $0.78 \pm 0.10(0.78) \dagger$ \\
\hline Tenting area $\left(\mathrm{cm}^{2}\right)$ & $1.50 \pm 0.91(1.3)$ & $0.44 \pm 0.25(0.44)^{*}$ & $0.45 \pm 0.27(0.47) \dagger$ \\
\hline Coaptation depth (mm) & $7.9 \pm 2.4(8)$ & $4.6 \pm 1.9(4.5)^{*}$ & $4.4 \pm 1.8(4) \dagger$ \\
\hline Coaptation length (mm) & $3.9 \pm 1.4(4)$ & $4.9 \pm 1.7(5.0)^{*}$ & $5.4 \pm 1.5(5.7) \dagger, \ddagger$ \\
\hline Functional mitral valve area $\left(\mathrm{cm}^{2}\right)$ & $3.1 \pm 0.6(3)$ & $3.1 \pm 0.4(3.1)$ & $3.0 \pm 0.8(3)$ \\
\hline Mean gradient $(\mathrm{mm} \mathrm{Hg})$ & & $3.7 \pm 1.0(3.8)$ & $3.7 \pm 2.0(3.4)$ \\
\hline
\end{tabular}

was related to neither ventricular remodeling nor postoperative change in EF.

\section{Postoperative Echocardiography}

All 127 survivors had a postoperative echocardiogram performed 1 to 3 months after surgery and after a mean follow-up of $18 \pm 6$ months. The 10 patients in whom a mitral prosthesis had been inserted were in NYHA class I or II, and none showed continuous remodeling.

In 117 patients who underwent MV repair (Table 2), mean ERO changed from $34.1 \pm 10.2 \mathrm{~mm}^{2}$ to $2.3 \pm 0.4 \mathrm{~mm}^{2}$ $(P<.001)$. In total, 81 patients had no mitral regurgitation, 27 had mitral regurgitation with ERO 1 to $9 \mathrm{~mm}^{2}$, and 9 had mitral regurgitation with ERO 10 to $19 \mathrm{~mm}^{2}$. No patient had worsened mitral regurgitation grade. Ninety-eight patients were discharged from the hospital with no residual mitral regurgitation; only 16 of these showed ERO 1 to $9 \mathrm{~mm}^{2}$ on follow-up. In contrast, 9 patients of 19 who at discharge had residual mitral regurgitation with ERO 1 to $9 \mathrm{~mm}^{2}$ showed progression of mitral regurgitation (Table 3). Freedom from both death from any cause and from mitral regurgitation with ERO at least $10 \mathrm{~mm}^{2}$ was $83 \% \pm 5 \%$.

The 20 patients who died had undergone postoperative echocardiography from 3 days to 7 months after surgery. All of them had no $(n=13)$ or residual mitral regurgitation with ERO 1 to $9 \mathrm{~mm}^{2}(\mathrm{n}=7)$, mean $1.8 \pm 0.3$. Patients who died in the first 30 days had a trend toward lower ventricular volumes than seen in patients who survived the first 30 days (end-diastolic volume $66 \pm 23 \mathrm{~mL} / \mathrm{m}^{2}$ vs $82 \pm 26 \mathrm{~mL} / \mathrm{m}^{2}$ and ESV $42 \pm 18 \mathrm{~mL} / \mathrm{m}^{2}$ vs $53 \pm 22 \mathrm{~mL} / \mathrm{m}^{2}$ ).

\section{Ventricular Remodeling}

Of the 117 patients who underwent MV repair, 69 $(59.0 \%)$ had reverse remodeling occur, 40 (34.1\%) had no remodeling occur, and $8(6.9 \%)$ had continuous remodeling occur. No patient who showed reverse remodeling had mitral regurgitation progression to ERO of at least $10 \mathrm{~mm}^{2}$ $(0 / 69)$, whereas the incidences of such progression were $7.5 \%$ when no remodeling occurred $(3 / 40)$ and $75 \%(6 / 8)$ if remodeling continued, $(P<.001)$. Remodeling was

TABLE 3. Change of mitral regurgitation grade according to the preoperative mitral regurgitation grade and the early postoperative mitral regurgitation grade

\begin{tabular}{|c|c|c|c|c|c|c|}
\hline \multirow{2}{*}{$\begin{array}{c}\text { Preoperative } \\
\text { effective } \\
\text { regurgitant } \\
\text { orifice }\left(\mathrm{mm}^{2}\right)\end{array}$} & \multicolumn{4}{|c|}{$\begin{array}{l}\text { Effective regurgitant orifice } \\
\left(\mathrm{mm}^{2}\right) \text { after } 18 \text { mo follow-up }\end{array}$} & \multirow[b]{2}{*}{ Total } & \multirow[b]{2}{*}{$P$ value } \\
\hline & 0 & 1-9 & 10-19 & $\geq 20$ & & \\
\hline \multicolumn{7}{|l|}{ All } \\
\hline $1-9$ & 4 & 1 & - & - & 5 & .852 \\
\hline 10-19 & 9 & 3 & 2 & - & 15 & \\
\hline$\geq 20$ & 68 & 22 & 7 & - & 97 & \\
\hline \multicolumn{7}{|l|}{ Early } \\
\hline 0 & 78 & 20 & - & - & 98 & $<.001$ \\
\hline $1-9$ & 3 & 7 & 9 & - & 19 & \\
\hline
\end{tabular}


influenced by higher ESV (the receiver operating characteristic curve showed a cutoff at $\geq 60 \mathrm{~mL} / \mathrm{m}^{2}$ ) and by low preoperative EF (Table 4).

Comparing early (1 to 3 months) and late ESV modification, none of the patients who showed no remodeling or reverse remodeling had worsening to continuous remodeling.

\section{EF Modifications}

EF improved in 47 cases, remained unchanged in 63, and worsened in 7. Only in 68 patients (Table E2) did ventricular remodeling and EF modifications coincide, whereas in 49 the modifications were dissimilar, with patients with reverse remodeling showing no EF change. Comparing early and late $\mathrm{EF}$ modifications, no patient with early improvement had late worsening.

\section{Mitral Prosthesis Insertion}

In 10 patients, a mitral prosthesis was inserted because $\mathrm{CD}$ was greater than $10 \mathrm{~mm}$. Preoperatively, these patients showed a trend toward a higher indexed ESV ( $67 \pm 18$ vs $54 \pm 22, P=.07)$, whereas $\mathrm{EF}(31 \% \pm 5 \%$ vs $35 \% \pm$ $9 \%$, difference not significant) and ERO $\left(39 \pm 8 \mathrm{~mm}^{2}\right.$ vs $36 \pm 11 \mathrm{~mm}^{2}$, difference not significant) did not differ from those in the rest of the population. All patients survived and were in NYHA class I $(\mathrm{n}=8)$ or II $(\mathrm{n}=2)$ at follow-up. Seven patients showed reverse remodeling, and 3 showed no remodeling.

\section{DISCUSSION}

The main findings of this study were as follows: (1) Close to $40 \%$ of the patients who underwent MV surgery for CIMR underwent more than isolated annuloplasty. (2) Reverse remodeling is frequent and is more frequent among patients with larger volumes and lower EF. (3) In the midterm, functional results did not depend on ventricular remodeling or on EF changes. (4) Patients who were discharged with no residual mitral regurgitation did not show mitral regurgitation grade with ERO of at least $20 \mathrm{~mm}^{2}$ at follow-up.

TABLE 4. Factors influencing ventricular remodeling

\begin{tabular}{lccccc}
\hline & \multicolumn{5}{c}{ Remodeling } \\
\cline { 2 - 6 } & Reverse & None & Continuous & Total & P value \\
\hline End-systolic volume & & & & \\
$\geq 60 \mathrm{~mL} / \mathrm{m}^{2}$ & 35 & 4 & 1 & 40 & $<.001$ \\
$<60 \mathrm{~mL} / \mathrm{m}^{2}$ & 34 & 36 & 7 & 77 & \\
\multicolumn{2}{l}{$\begin{array}{l}\text { Postoperative effective regurgitant orifice } \\
0-9 \mathrm{~mm}^{2}\end{array} \quad 69$} & 37 & 2 & 108 & $<.001$ \\
$\geq 10 \mathrm{~mm}^{2}$ & 0 & 3 & 6 & 9 & \\
Preoperative ejection fraction & & & & \\
$\leq 30 \%$ & 30 & 8 & 3 & 41 & .011 \\
$31-40 \%$ & 17 & 6 & 3 & 26 & \\
$>40 \%$ & 22 & 26 & 2 & 50 & \\
\hline
\end{tabular}

The natural history of CIMR is not favorable. The presence of CIMR after myocardial infarction has been demonstrated to be related to lower survival, in particular when ERO is at least $20 \mathrm{~mm}^{2} .5$ The excess mortality was independent of both the EF and the functional status. Any grade of CIMR, as measured by ERO, has been seen to be related at 5 years to higher incidences of congestive heart failure and of the combined end points of congestive heart failure and cardiac-related death. ${ }^{8}$ CIMR left untreated when coronary artery bypass grafting was performed has also been shown to be followed by a worse long-term outcome. Our group previously demonstrated that results of coronary artery bypass grafting alone in patients with CIMR $2+$ were poor if EF was no greater than $30 \%,{ }^{9}$ and freedoms from cardiac-related death and from cardiac events were reduced in patients with EF $31 \%$ to $40 \%$ and CIMR $1+$ or $2+{ }^{10}$

On the basis of these observations, some patients with mild CIMR could benefit from MV repair. To identify such a subgroup, we prefer to address echocardiographic MV anatomy. When septolateral dimension or the ratio of septolateral dimension to AL length is equal or superior to the median value of patients with CIMR that is moderate or worse $(27 \mathrm{~mm}$ and 1.02 , respectively), we hypothesize that MV anatomy is abnormal and that further worsening is more likely to happen than in patients with mild CIMR and less abnormal mitral dimensions. The clinical impact of this problem is, however, very limited, because only 5 patients with ERO between 1 and $9 \mathrm{~mm}^{2}$ were surgically treated.

The basic technique to repair functional CIMR is downsizing annuloplasty, introduced by Bolling and colleagues. ${ }^{11}$ Even if the same authors ${ }^{12}$ were not able to demonstrate any benefit in survival when comparing treated and untreated patients, others ${ }^{13}$ found annuloplasty to improve the clinical status. The main problem of the surgical treatment of CIMR, however, is mitral regurgitation's return (or residual mitral regurgitation), being present, with different percentages in all the reports. ${ }^{14-16}$ Annuloplasty alone is not the only option for surgical treatment of CIMR; in close to $40 \%$ of our patients, additional solutions were applied.

CIMR is a ventricular disease, because the mechanism of closure of the MV is affected by displacement of the posteromedial (asymmetric displacement) or both (symmetric displacement) papillary muscles. Consequences of these changes are regurgitation of different grade and deepening of the $\mathrm{CD}$. There is a range of anatomic and functional modifications of the MV which still allows to correct the regurgitation, with overreductive annuloplasty, combining or not with other techniques. There is, however, a cutoff point at which conservative techniques do not pay in the midterm or long term. Different indicators $\left(\mathrm{CD},{ }^{6}\right.$ degree of papillary muscle displacement, ${ }^{17}$ angles between the posterior ${ }^{18}$ or anterior ${ }^{19}$ mitral leaflets and the annular plane) were used as surrogates for the ventricular modifications that could sustain mitral regurgitation return. 
To reduce the incidence of mitral regurgitation return, our group proposed that a $\mathrm{CD}$ of $10 \mathrm{~mm}$ be used as cutoff point to separate cases in which MV repair could be performed from those in which chordae-sparing implantation of a prosthesis was the preferable solution. ${ }^{6}$ Long-term survivals among patients who underwent MV repair and replacement were found to be similar by Al-Radi and coworkers ${ }^{20}$ and Magne and associates. ${ }^{21}$

When the AL length is shorter than $25 \mathrm{~mm}$, augmentation of the leaflet can be obtained with a pericardial patch, as suggested by Kinkaid and colleagues, ${ }^{22}$ to increase the CL. When the AL was augmented, the second-order chordae were always cut, to increase the mobility of the leaflet. Selective chordal cutting was performed in 7 cases, because limitation of AL excursion will reduce the CL. Even if chordal cutting is still controversial, our results were excellent, at least in the midterm.

In our opinion, ventricular scar exclusion, when possible, can be a valid tool to increase the benefit of MV surgery. Ventricular scarring, as demonstrated by Srichai and coworkers, ${ }^{23}$ is significantly increased in patients with severe CIMR. Braun and colleagues ${ }^{15}$ showed reduced survival and lack of reverse ventricular remodeling among patients with diastolic left ventricular dimensions greater than 65 $\mathrm{mm}$. They advocated, for these patients, a concomitant ventricular approach. Other studies have emphasized the necessity of adding some ventricular procedure in case of enlarged cardiac dimensions. ${ }^{19}$ We believe that, in the presence of increased left ventricular volumes, ventricular scar exclusion is part of the surgical strategy for CIMR treatment to prevent mitral regurgitation return.

Applying all these technical solutions, reverse remodeling was present in $59 \%$ of the survivors who underwent mitral repair, and only $6.9 \%$ showed continuous remodeling. It is debatable whether the result can be considered favorable when no remodeling is present, because maintaining a similar systolic function without, or with less, mitral regurgitation could have a positive effect on long-term results; however, only patients with reverse remodeling showed no or mild residual mitral regurgitation. Reverse remodeling was more likely to happen in patients with larger volumes and lower EF, but it is noteworthy that, independent of the quality of remodeling, functional results are good, at least in the midterm.

Interestingly, only patients discharged with mild mitral regurgitation (ERO 1-9 $\mathrm{mm}^{2}$ ) showed further mitral regurgitation progression from mild to moderate. It is still not clear whether something different from isolated annuloplasty could further reduce the incidence of moderate or severe mitral regurgitation in the follow-up. Magne and coworkers ${ }^{18}$ showed that a posterior leaflet angle of at least $45^{\circ}$ predicted mitral regurgitation return, even if $\mathrm{CD}$ was 10 $\mathrm{mm}$ or less. Perhaps this parameter could be helpful in identifying more patients in whom annuloplasty alone has to be abandoned. Very likely a larger use of MV prosthetic insertion would contribute to improved long-term results; surgeons are still reluctant, however, because this is considered a surgical failure.

Downsizing annuloplasty was obtained with a flexible 40-mm long band. Because use of a device to reshape the annulus is crucial, we decided to respect at maximum the morphologic and functional properties of the mitral annulus, maintaining the systodiastolic narrowing of the annulus (to reduce the gradients in diastole and to increase the coaptation in systole; Table 2) and its saddle shape (which reduces the stress on the leaflets and keeps the AL in a preopening position; Figure E1). Similar findings have been reported by others. ${ }^{24}$ Caimmi and colleagues,${ }^{25}$ comparing in a magnetic resonance imaging study partial flexible (SMB40 and SMB50) and rigid complete (St Jude, saddle ring) circumferential rings, found that left ventricular outflow dynamics and AL movements are significantly impaired when a rigid circumferential ring is used, blocking the lower part of the aortomitral membrane physiologic movement. These changes are not present when the SMB40 or SMB50 is used.

The use of the same size band for every patient facilitates surgery but needs further comments. The rationale is based on the fact that the septolateral distance we achieve with the SMB40 is $21 \mathrm{~mm}$. Because the length of the AL has small variability (mean $27.5 \pm 2.3 \mathrm{~mm}$ and median 27 $\mathrm{mm}$, with only a few patients having an AL length $<25$ $\mathrm{mm})$. in the great majority of cases such a band will allow a good CL of $5 \mathrm{~mm}$ or more. In the remaining cases, AL augmentation will be able to obtain again a longer CL. Anyway, in most series only 1 or 2 sizes (ring or band) are practically used.

\section{Limitations of the Study}

This was a retrospective study, but it included all the patients who underwent CIMR, independent of the location of the myocardial infarction, as it happens in the real world. Mean EF was only $35 \%$, but a third of the patients had $\mathrm{EF}$ of $30 \%$ or less, mirroring the EF distribution in the real world. The anatomic and functional aspects of the MV were different, just as are the functional consequences of ventricular disease on the pathophysiology of the MV. The follow-up was relatively short, but most of the adverse outcomes after surgery for functional CIMR are seen in the early follow-up. The main weakness of this study is the lack of a control group; this reduces the possibility of validating correctly the algorithm that we propose. A large variety of surgical approaches were used on relatively small number of patients. Although this probably reflects the complexity of this disease process and the lack of consensus regarding its treatment, it also significantly reduces our ability to make scientifically valid conclusions from our data. Myocardial viability was not routinely assessed, because regional wall abnormalities together with myocardial infarction in the 
same area made the study not necessary. We are aware that this may affect our conclusions on postoperative left ventricular remodeling and functional mitral regurgitation recurrence.

\section{CONCLUSIONS}

In conclusion, surgery for CIMR must consider the mechanisms and the effects of the underlying ventricular disease on the MV. Fewer than $10 \%$ of patients need prosthetic insertion. In the remaining cases repair can be performed, but only a careful observation of the echocardiographic anatomy of the MV can dictate the most appropriate technique for surgical correction of CIMR.

\section{References}

1. Grossi EA, Goldberg JD, LaPietra A, Ye X, Zakow P, Sussman M, et al. Ischemic mitral valve reconstruction and replacement: comparison of long-term survival and complications. J Thorac Cardiovasc Surg. 2001;122:1107-24.

2. McGee EC, Gillinov AM, Blackstone EH, Rajeswaran J, Cohen G, Najam F, et al. Recurrent mitral regurgitation after annuloplasty for ischemic mitral regurgitation. J Thorac Cardiovasc Surg. 2004;128:916-24.

3. Kim YH, Czer LS, Soukiasian HJ, De Robertis M, Magliato KE, Blanche C, et al. Ischemic mitral valve regurgitation: revascularization alone versus revascularization and mitral valve repair. Ann Thorac Surg. 2005;79:1895-901.

4. Serri K, Bouchard D, Demers P, Coutu M, Pellerin M, Carrier M, et al. Is a good perioperative echocardiographic result predictive of durability in ischemic mitral valve repair? J Thorac Cardiovasc Surg. 2006;131:565-73.

5. Grigioni F, Enriquez-Sarano M, Zehr KJ, Bailey KR, Tajik AJ. Ischemic mitral regurgitation. Long term outcome and prognostic implication with quantitative Doppler assessment. Circulation. 2001;103:1759-64.

6. Calafiore AM, Di Mauro M, Gallina S, Di Giammarco G, Iacò AL, Teodori G, et al. Mitral valve surgery for ischemic mitral regurgitation. Ann Thorac Surg. 2004;77:1989-97.

7. Calafiore AM, Di Mauro M, Di Giammarco G, Gallina S, Iacò AL, Contini M, et al. Septal reshaping for exclusion of anteroseptal dyskinetic or akinetic areas. Ann Thorac Surg. 2004;77:2115-21.

8. Grigioni F, Detaint D, Avierinos JF, Scott C, Tajik J, Enriquez-Sarano M. Contribution of ischemic mitral regurgitation to congestive heart failure after myocardial infarction. J Am Coll Cardiol. 2005;45:260-7.

9. Di Mauro M, Di Giammarco G, Vitolla G, Contini M, Iacò AL, Bivona A, et al. Impact of no-or-moderate mitral regurgitation on late results after isolated coronary artery bypass grafting in patients with ischemic cardiomyopathy. Ann Thorac Surg. 2006;81:2128-34.

10. Calafiore AM, Mazzei V, Iacò AL, Contini M, Bivona A, Gagliardi M, et al. Impact of ischemic regurgitation on long-term out come of patients with ejection fraction above 0.30 undergoing first isolated myocardial revascularization. Ann Thorac Surg. 2008;86:458-65.

11. Bolling SF, Pagani FD, Deeb GM, Bach DS. Intermediate-term outcome of mitral reconstruction in cardiomyopathy. J Thorac Cardiovasc Surg. 1998; 115:381-6.

12. Wu AH, Aaronson KD, Bolling SF, Pagani FD, Welch K, Koelling TM. Impact of mitral valve annuloplasty on mortality risk in patients with mitral regurgitation and left ventricular systolic dysfunction. J Am Coll Cardiol. 2005;45:381-7.

13. Fattouch K, Guccione F, Sampognaro R, Panzarella G, Corrado E, Navarra E, et al. POINT: Efficacy of adding mitral valve restrictive annuloplasty to coronary artery bypass grafting: a randomized trial. J Thorac Cardiovasc Surg. 2009;138: 278-85.

14. Mihaljevic T, Lam BK, Rajeswaran J, Takagaki M, Lauer MS, Gillinov M, et al. Impact of mitral valve annuloplasty combined with revascularization in patients with functional ischemic mitral regurgitation. J Am Coll Cardiol. 2007;49: 2191-201.

15. Braun J, van de Veire NR, Klautz RJ, Versteegh MI, Holman ER, Westenberg JJ, et al. Restrictive mitral annuloplasty cures ischemic mitral regurgitation and heart failure. Ann Thorac Surg. 2008;85:430-7.

16. Gelsomino S, Lorusso R, De Cicco G, Capecchi I, Rostagno R, Caciolli S, et al. Five-year echocardiographic results of combined undersized mitral ring annuloplasty and coronary artery bypass grafting for chronic ischemic mitral regurgitation. Eur Heart J. 2008;29(231):40.

17. Roshanali F, Mandegar MH, Yousefnia MA, Rayatzadeh H, Alaeddini F. A prospective study of predicting factors in ischemic mitral regurgitation recurrence after ring annuloplasty. Ann Thorac Surg. 2007;84:745-9.

18. Magne J, Pibarot P, Degenais F, Hachicha Z, Dusmenil JG, Sénéchal M. Preoperative posterior leaflet angle predicts outcome after restrictive mitral valve annuloplasty for ischemic mitral regurgitation. Circulation. 2007;115:782-91.

19. Gelsomino S, Lorusso R, Caciolli S, Capecchi I, Rostagno C, Chioccioli M, et al. Insights on left ventricular and valvular mechanisms of recurrent ischemic mitral regurgitation after restrictive annuloplasty and coronary artery bypass grafting. J Thorac Cardiovasc Surg. 2008;136:507-18.

20. Al-Radi OO, Austin PC, Tu JV, David TE, Yau TM. Mitral repair versus replacement for ischemic mitral regurgitation. Ann Thorac Surg. 2005;79:1260-7.

21. Magne J, Girerd N, Sénéchal M, Mathieu P, Dagenais F, Dusmenil JC, et al. Mitral repair versus replacement for ischemic mitral regurgitation: comparison of shortterm and long-term survival. Circulation. 2009;120(11 Suppl):S104-11.

22. Kinkaid EH, Riley RD, Hines MH, Hammon JW, Kon ND. Anterior leaflet augmentation for ischemic mitral regurgitation. Ann Thorac Surg. 2004;78: 564-8.

23. Srichai MB, Grimm RA, Stillman AE, Gillinov M, Rodriguez LL, Lieber ML, et al. Ischemic mitral regurgitation: impact of left ventricle and mitral valve in patients with left ventricular dysfunction. Ann Thorac Surg. 2005;80:170-8.

24. Gillinov AM, Cosgrove DM 3rd, Shiota T, Qin J, Tsujino H, Stewart WJ, et al. Cosgrove-Edwards annuloplasty system: midterm results. Ann Thorac Surg. 2000;69:717-21.

25. Caimmi PP, Diterlizzi M, Grossini E, Kapetanakis EI, Gavinelli M, Carriero A, et al. Impact of prosthetic mitral rings on aortomitral apparatus function: a cardiac magnetic imaging study. Ann Thorac Surg. 2009;88:740-4. 


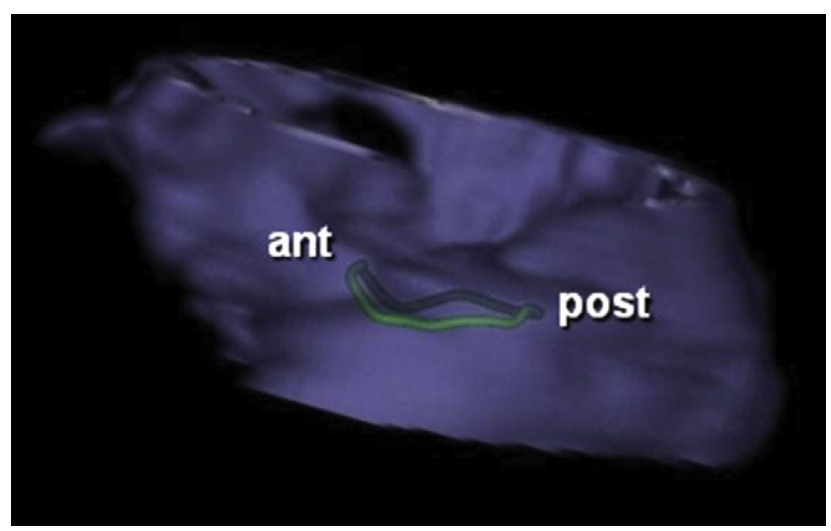

FIGURE E1. Three -dimensional reconstruction of mitral annulus 2 years after surgical correction of chronic ischemic mitral regurgitation with SMB40. Saddle shape of mitral annulus is maintained. Transesophageal echocardiographic study was performed with Acuson Sequoia C 512 (Siemens, Munich, Germany) equipped with Tomtec software (Tomtec Imaging Solution, Unterschleissheim, Germany). ant, Anterior annulus; post, posterior annulus.

TABLE E1. Systolic septolateral diameter and systolic septolateral diameter/anterior leaflet length ratio according the preoperative effective regurgitant orifice

\begin{tabular}{lcc}
\hline $\begin{array}{c}\text { Preoperative effective } \\
\text { regurgitant orifice }\left(\mathbf{m m}^{\mathbf{2}}\right)\end{array}$ & SSL $(\mathbf{m m})$ & $\begin{array}{c}\text { SSL/anterior leaflet } \\
\text { length ratio }\end{array}$ \\
\hline $1-9$ & $28.7 \pm 2.5(28.5)$ & $1.03 \pm 0.11(1.04)$ \\
$10-19$ & $27.6 \pm 3.5(27)$ & $1.04 \pm 0.15(1.00)$ \\
$\geq 20$ & $27.7 \pm 2.5(27)$ & $1.04 \pm 0.12(1.04)$ \\
$\geq 10$ & $27.6 \pm 2.6(27)$ & $1.04 \pm 0.13(1.02)$ \\
\hline Data are expressed as mean \pm SD and median. $S S L$, Systolic septolateral diameter.
\end{tabular}

TABLE E2. Modification of ejection fraction compared with ventricular remodeling

\begin{tabular}{lccc}
\hline & \multicolumn{3}{c}{ Left ventricular remodeling } \\
\hline Ejection fraction & Reverse & None & Continuous \\
Improved $(\geq 15 \%)$ & 39 & 7 & 1 \\
Stable $(-14.9 \%$ to $+14.9 \%)$ & 27 & 29 & 7 \\
worsened $(\leq 15 \%)$ & 3 & 4 & - \\
\hline
\end{tabular}

